\title{
Are personality characteristics of Clinical Nurse Leader graduate nursing students related to culturally competent nursing care?
}

\author{
Kathleen M. Nokes ${ }^{* 1}$, Mattia J. Gilmartin ${ }^{2}$ \\ ${ }^{1}$ Hunter College and Graduate Center, City University of New York, New York, United States \\ ${ }^{2}$ College of Nursing, New York University, New York, United States
}

\author{
Received: January 6, 2015 \\ Accepted: February 4, 2015 \\ Online Published: February 10, 2015 \\ DOI: $10.5430 /$ jnep.v5n5p1 \\ URL: http://dx.doi.org/10.5430/jnep.v5n5p1
}

\begin{abstract}
Health policies increasingly address the need to eliminate disparities in healthcare and it is imperative that nurses identify how they contribute to achievement of that goal. The purpose of this descriptive, cross-sectional research was to identify if there is relationship between a core personality trait, core self-evaluations, and confidence in the ability of beginning graduate nursing students $(\mathrm{N}=71)$ in a Clinical Nurse Leader (CNL) track to deliver culturally competent nursing care. A partial correlation, controlling for age, pre-licensure nursing education program, race, and satisfaction with current nursing position, found that core self-evaluations were significantly related to the three subscales on the transcultural self-efficacy scale, specifically: cognitive $(r=.417, p=.001)$; affective $(r=.479, p=.000)$; and practical $(r=.521, p=.000)$ self-efficacy. The relatively low core self-evaluations for this group of nurses in the early phases of graduate education for the CNL role compared to other samples is less than desirable for persons who are embracing a new nursing role that requires leadership skills to inspire followers. Although core self-evaluations are a relatively stable personality characteristic, educational programs could incorporate strategies to improve core self-evaluations in order to assist professionals to appraise their workplace challenges in a more positive framework.
\end{abstract}

Key Words: Clinical nurse leader, Graduate nursing education, Transcultural self-efficacy, Core self-evaluations, Educational research

\section{INTRODUCTION}

Health disparities among racial and ethnic minorities in the United States are well documented. ${ }^{[1]}$ Increasingly, health care professionals and organizations seek to develop interventions that bridge racial, cultural and linguistic barriers to improve the quality of care with the ultimate goal of improving health outcomes among racial and ethnic minorities. ${ }^{[2]}$ Current health care reform efforts place renewed emphasis on mitigating disparities in care that stem from racial and ethnic differences between patients and health care providers. For example, under the Patient Protection and Affordable Care Act, ${ }^{[3]}$ healthcare organizations are mandated to report clinical performance data segmented by population characteristics such as race, ethnicity, and language proficiency as a means to identify disparities in care and prioritize improvement efforts.

Addressing health disparities will take multidimensional approaches involving change among providers, care teams,

* Correspondence: Kathleen M. Nokes; Email: kathynokes@aol.com; Address: Hunter College and Graduate Center, City University of New York, 868 Buck Road, Stone Ridge, New York, United States. 
organizations, and communities. ${ }^{[2]}$ The nursing code for ethics requires practice with compassion irrespective of the personal characteristics of diverse racial, cultural, religious, sexual, and socio-economic groups. ${ }^{[4]}$ Nurses play a key role in reducing health disparities by virtue of the professions' focus on symptom management, health promotion, and disease prevention.

Quality health care includes both technical (e.g., prescribing the correct medication) and service elements (e.g., personalized care plan) and health professionals' cultural competence is one way to promote the interpersonal aspects associated with service quality in general, and patient-centered care, more specifically. Cultural competence is a set of congruent behaviors, attitudes, and policies that come together in a system, agency, or among professionals that enables effective work in cross-cultural situations. ${ }^{[5]}$ Nurses and other health professionals tailor care that takes clients' cultural beliefs and personal preferences into account as a patient-focused plan of care is designed and implemented. In a study of hospitals in California, Weech-Maldonado and colleagues ${ }^{[6]}$ found that the cultural competence of nurses and other nonphysician providers influenced minorities' perceptions of the quality of care being received. Hospitals with greater cultural competency scores had higher consumer ratings on the national hospital consumer assessment of healthcare providers and systems survey (HCAHPS) on the nurse communication, staff responsiveness, quietness, and pain control dimensions.

In recent years, the emergence of the Clinical Nurse Leader (CNL), a point-of-care role specifically designed to promote the nursing professions' contribution to achieve the triple aim of clinical quality improvement, population health and cost reduction ${ }^{[7]}$ holds particular promise for championing organizational initiatives focused on reducing disparities in care among minority groups. A growing body of evidence documents CNLs' contributions to enhancing the quality and effectiveness of care, promoting patient satisfaction, and leading system redesign projects. ${ }^{[8]}$ For example, CNLs are well prepared to design and implement quality improvement programs targeting specific minority groups (e.g., African Americans), or specific diseases with high prevalence rates (e.g., Type II diabetes) in a particular patient populations. ${ }^{[9-13]} \mathrm{Be}-$ cause CNLs are often tasked with unit-level responsibility for managing the patient experience, ${ }^{[12,14]}$ promoting cultural competence within this group of nurses holds promise for accelerating improvement efforts focused on providing care that reflects the cultural preferences of diverse clients, including members of racial and ethnic minority groups. Ong-Flaherty ${ }^{[15]}$ described the practice of CNL students in a free clinic in a socio-economically depressed area serving the homeless, streetwalkers, and transgender individuals.
This study examines the extent to which nurses in the early phases of graduate education for the CNL role are confident in their abilities to deliver culturally competent nursing care and contributes to the transcultural nursing and the CNL role development literature in two important ways. First, we contribute to the transcultural competence literature by examining this concept in a racially diverse sample of registered nurses in the early phase of graduate education. To date, the research on nurses' transcultural competence has focused mainly on undergraduate students entering the workforce, ${ }^{[16,17]}$ nurse faculty's confidence in teaching content on culturally appropriate nursing care, ${ }^{[18]}$ or practicing clinicians' confidence with incorporating client's cultural preferences into their practice routines. ${ }^{[19]}$ Second, we add to the evolving literature that examines the role of personality in nurses' effectiveness in the high profile CNL role. ${ }^{[20,21]}$

This purpose of this evaluation research was to provide descriptive data about the association between a core personality trait drawn from the organizational psychology literature $^{[22]}$ that has received little attention in the nursing-specific leadership research ${ }^{[23,24]}$ and perceptions of the ability to deliver culturally-appropriate nursing care, an important aspect of contemporary nursing practice.

\subsection{Transcultural self-efficacy}

An important predisposing factor for delivering culturally competent care is transcultural self-efficacy which is the belief in one's own knowledge, attitudes, and abilities to interact with another person who is from a different cultural, ethnic, or religious group than one's own. ${ }^{[25]}$ Whereas most efforts in promoting health professionals' cultural competency skills focus on developing knowledge, skills and attitudes in providing care to people with different cultural or religious beliefs ${ }^{[2]}$ than one's own, the role of providers' personality in providing culturally competent care is largely absent. The cultural competence and confidence model is a theoretical framework for teaching cultural competence which includes the construct of transcultural self-efficacy (confidence) as a major influencing factor. Cultural competence is defined as a multidimensional learning process that integrates transcultural skills in all three educational learning domains (cognitive, practical, and affective). ${ }^{[26]}$

\subsection{Core self-evaluations}

Core self-evaluations reflect beliefs about self-worth, one's capabilities to control one's life, competence to perform, cope, persevere, succeed, and have a general sense that life will turn out well. ${ }^{[22]}$ Core self-evaluations are a relatively stable higher order multidimensional personality trait that was created from the four lower order traits of self-esteem, 
locus of control, emotional stability (neuroticism), and generalized self-efficacy. ${ }^{[27]}$ Individuals with high core selfevaluations are more likely to focus on the positive aspects of their environment. Core self-evaluations have been shown to influence a range of career behaviors including the types of jobs and occupations that individuals select, employment stability, and perceptions of work and experiences at work. ${ }^{[28]}$ In turn, higher core self-evaluations predict job satisfaction, job performance, and career success. ${ }^{[29]}$ Although the core self-evaluation construct is well established in psychology and management research, ${ }^{[30]}$ it has received relatively little attention in the nursing-specific research (see Table 1). To date, the core self-evaluations of nurses have been studied in Taiwan and Canada. ${ }^{[23,24,30,31]}$ No studies could be located that studied core self-evaluations in a United States sample of registered nurses.
In a series of studies examining staff nurses' perceptions of their work environments, Laschinger and colleagues ${ }^{[24]}$ found that nurses' core self-evaluations were a significant predictor of burnout and emotional exhaustion. Nurses with low core self-evaluations were more likely to experience greater emotional exhaustion and cynicism, which reduced their level of job satisfaction ${ }^{[23]}$ ); and nurses' core self-evaluations directly influenced their levels of job stress, suggesting that more positive core self-evaluations may be more effective in reducing work stress than the ability to manage interpersonal conflict. ${ }^{[31]}$ In a study of Taiwanese nurses, Chang and colleagues ${ }^{[30]}$ adapted the core self-evaluation scale by removing locus of control and substituted other traits that they believed were more culturally appropriate and found that those traits were significantly related to job satisfaction.

Table 1. Core self-evaluations in different samples

\begin{tabular}{|c|c|c|c|c|}
\hline Author & Sample & $\mathbf{N}$ & Mean & SD \\
\hline & 1. Employees in a food service company & 280 & 3.83 & .48 \\
\hline Judge, Erez, Bono \& & 2. Pharmaceutical salesperson & 175 & 4.03 & .58 \\
\hline \multirow[t]{2}{*}{ Thorensen (2003) } & 3. Undergraduates, southwestern university & 265 & 3.83 & .57 \\
\hline & 4. Undergraduates, mid-western university & 126 & 3.78 & .50 \\
\hline $\begin{array}{l}\text { Besen, Matz-Costa, } \\
\text { Brown, Smyer \& } \\
\text { Pitt-Catsouphes (2013) }\end{array}$ & Multi-worksite sample of employed adults & 1873 & $\begin{array}{l}4.45^{*} \\
\text { (adjusted for } 5 \text { point } \\
\text { scale: } \underline{3.70} \text { ) }\end{array}$ & .67 \\
\hline $\begin{array}{l}\text { Laschinger, Finegan \& } \\
\text { Wilk (2011) }\end{array}$ & Nurses from 217 hospital units in Ontario Canada & 3156 & $\begin{array}{l}5.22 * * \text { (adjusted for } 5 \\
\text { point scale: } \underline{3.72} \text { ) }\end{array}$ & .78 \\
\hline $\begin{array}{l}\text { Almost, Doran, Hall \& } \\
\text { Laschinger (2010) }\end{array}$ & Nurses working in acute care areas in Canada & 277 & 3.83 & .52 \\
\hline $\begin{array}{l}\text { Laschinger, \& Finegan } \\
\text { (2008) }\end{array}$ & Nurse managers in Canada & 134 & $\begin{array}{l}5.12^{* *} \\
\text { (adjusted for } 5 \text { point } \\
\text { scale: } \underline{3.65} \text { ) }\end{array}$ & .85 \\
\hline $\begin{array}{l}\text { Greenbaum, Mawritz \& } \\
\text { Eissa (2012) }\end{array}$ & $\begin{array}{l}\text { Employees in organizations located in the } \\
\text { southeastern United States in industries including } \\
\text { hospitality, retail, accounting, education, } \\
\text { manufacturing, banking, and food service. }\end{array}$ & $\begin{array}{l}113 \text { focal worker/ } \\
\text { coworker/supervisor } \\
\text { triads. }\end{array}$ & $\begin{array}{l}5.28 * * \text { (adjusted for } 5 \\
\text { point scale: } \underline{3.98} \text { ) }\end{array}$ & .95 \\
\hline $\begin{array}{l}\text { Stanhope, Pond \& } \\
\text { Surface (2013) }\end{array}$ & $\begin{array}{l}\text { Military personnel who participated in job-required } \\
\text { training }\end{array}$ & 638 & 4.03 & .53 \\
\hline $\begin{array}{l}\text { Nokes \& Gilmartin } \\
\text { (current study) }\end{array}$ & CNL graduate nursing students & 71 & 3.558 & .43 \\
\hline
\end{tabular}

*6 point Likert scale used; **7 point Likert scale used.

\section{METHOD}

\subsection{Design}

The empirical setting for this study is a school of nursing within a large public university system located in the midAtlantic region of the United States. The CNL program is one specialization track in a larger MSN program $(\mathrm{N}=543)$ preparing graduates for roles as nurse practitioners, clinical nurse specialists, advanced public health nurses, and nurse managers. Approximately fifty percent of the school's grad- uate students are enrolled in the nurse practitioner program. The CNL program, designed for participants with a bachelor's degree in nursing (Model A), opened in the fall of 2009; its implementation was supported by a three year grant from the Health Resources Services Administration (2009-2012).

\subsection{Data collection}

To promote confidentiality, a team independent from the program faculty, conducted the program evaluation. The CNL 
students received invitation letters explaining the goals and objects of the program evaluation. The external evaluators were available before and after class on pre-arranged dates and times to review the study objectives, enroll the participants into the study, and collect the data. A maximum of four attempts were made to collect information including email, contact before or after a specified class, and hard copy mailed to their preferred address. The CNL program faculty did not review the de-identified data until after the research was completed. The study was approved by the Hunter College, City University of New York Institutional Review Board; all participants gave written informed consent. As a token of appreciation, study participants received a ballpoint pen with the CNL program logo at the first data collection point. Four cohorts of beginning graduate students participated during the period September, 2009 through September, 2012.

\subsection{Instruments}

Transcultural Self-Efficacy was measured with the Transcultural Self-Efficacy Tool (TSET) that assesses nursing students' confidence with performing general transcultural nursing skills. ${ }^{[32]}$ The 83 -item scale consists of the 1) cognitive, 2) practical, and 3 ) affective sub-scales. The cognitive subscale, consisting of 25 items, measures nurses' knowledge about the influence of cultural factors on planning and implementing nursing care. A sample item from the cognitive subscale is: "Among clients of different cultural backgrounds, how knowledgeable are you about the ways cultural factors may influence nursing care to obtain informed consent?" The 28 item practical subscale rates respondents' confidence in interviewing culturally diverse clients. A sample item from the practical subscale is: "How confident are you about interviewing clients of different cultural backgrounds to learn about their level of English comprehension?" The 30 item affective subscale addresses respondents' own values, attitudes, and beliefs. A sample item from the affective subscale is: "Among clients of different cultural backgrounds you recognize the need to prevent ethnocentric views." Respondents rate their confidence on each item using a 10 point Likert scale ranging from not confident (1) to totally confident (10). In this sample, Cronbach alpha reliabilities were .96 for the affective subscale, .98 for the cognitive subscale, and .99 for the practical subscale.

\subsubsection{Core self-evaluations}

Core self-evaluations were measured by the 12-item Core Self-evaluation Scale (CSES) developed by Judge and colleagues. ${ }^{[29]}$ The CSES measures the four personality traits of self-esteem; locus of control; emotional stability (neuroticism); and general self-efficacy. A sample item from the CSES is: "I am confident I get the success I deserve in life".
Items are measured on a 5 point Likert scale ranging from $1=$ strongly disagree to $5=$ strongly agree; half of the scale items (items 2, 4, 6, 8, 10, \& 12) are framed negatively and were recoded for the analyses. The measurement properties of the CSES are well established. ${ }^{[29]}$ In previous studies the reliability of the CSES, as measured by Cronbach's coefficient alpha, ranged from .81-.87. ${ }^{[22]}$ In our sample, the scale reliability computed using Cronbach's alpha was .81 .

\subsubsection{Participant characteristics}

We collected demographic, education and employment data using items from the national RN population sample survey. ${ }^{[33]}$

\subsection{Data analysis}

We used SPSS version 22 to analyze the data. After data were cleaned, the mean was imputed for missing data on the core self-evaluations and transcultural self-efficacy sub-scales. Descriptive statistics were conducted along with correlations, both Pearson Product Moment and partial correlations, using two-tailed and pairwise deletion.

\section{RESUltS}

Seventy one (71) of the 84 nurses enrolled in the first semester of the CNL track in the graduate program participated in the study, yielding a response rate of $85 \%$. Participant demographics are reported in Table 2. The average respondent was female, married, 38 years old, employed in nursing and moderately satisfied with his or her current job. Fifty six percent $(56 \%)$ of the respondents held a bachelor's degree as their initial educational preparation for practice. All respondents worked full-time and were enrolled in the graduate program on a part-time basis. Thirty eight percent (38\%) of the respondents were Black or African-American, and 16\% of the respondents were Asian or Pacific Islander.

The respondent's demographic characteristics are similar to other bachelor's and master's degree nursing graduates from the public university system to which our school of nursing belongs. According to the most recent data collected by the university, $67 \%$ of graduates from the bachelor's degree nursing programs were Black or African-American, Asian or Hispanic and an average age of 29.2 years old. Similarly, 53\% of nursing master's degree graduates was Black or African-American, Hispanic or Asian and an average age of 41.2 years old. Although our respondents share similar characteristics with students attending the public university system, they differ from the larger nursing population in the geographic region in terms of their racial and ethnic diversity. Of the estimated 462,000 registered nurses in the Mid-Atlantic region, $6.2 \%$ are Black and $7.3 \%$ are Asian. ${ }^{[33]}$ 
Table 2. Sample description $(\mathrm{N}=71)$

\begin{tabular}{|c|c|c|}
\hline & Item & $\mathbf{N}(\%)$ \\
\hline \multirow{5}{*}{ Qualifying educational program for RN license exam } & diploma & 01 (01.4\%) \\
\hline & associate degree & $23(32.4 \%)$ \\
\hline & bachelor's degree & $40(56.3 \%)$ \\
\hline & master’s degree & $03(04.2 \%)$ \\
\hline & missing & $04(05.6 \%)$ \\
\hline Graduation years & $1980-2012$ & Median: 2003 \\
\hline Licensed as LPN & Yes & $21(30 \%)$ \\
\hline Certified & Yes & $26(38.8 \%)$ \\
\hline Employed in nursing & Yes & $64(90 \%)$ \\
\hline \multirow{2}{*}{ Satisfaction with principal nursing position } & Mean (SD) & \multirow{2}{*}{$\begin{array}{l}\text { Range: } 1-5 \text { with } 1=\text { extremely dissatisfied } \\
\text { and } 5=\text { extremely satisfied }\end{array}$} \\
\hline & $3.65(1.05)$ & \\
\hline Number of years worked in nursing since licensing & Less than 1 year to 31 years & Median: 7 years \\
\hline \multirow{2}{*}{ Gender } & Female & $61(95 \%)$ \\
\hline & Male & $03(05 \%)$ \\
\hline Hispanic & Yes & $03(05 \%)$ \\
\hline \multirow{4}{*}{ Race } & Black/African American & $26(38 \%)$ \\
\hline & White & $17(25 \%)$ \\
\hline & Asian/Pacific Islander & $11(16 \%)$ \\
\hline & Other/missing & $17(21 \%)$ \\
\hline \multirow{4}{*}{ Marital status } & Single & $26(37 \%)$ \\
\hline & Married & $32(46 \%)$ \\
\hline & Living together as couple & $03(04 \%)$ \\
\hline & Divorced & $05(07 \%)$ \\
\hline Age & Range: 25 to 56 years & Median age: 38 years \\
\hline
\end{tabular}

The mean core self-evaluations score on the 5 point Likert type scale with higher scores indicating more positive core self-evaluations was $3.558(\mathrm{SD}=.432$, range $=2.84$ to 4.62). The three subscales of Transcultural Self-efficacy were all significantly correlated but there was a significant difference between the affective mean and standard deviation $(8.68,1.13)$ and either cognitive $(7.42,1.64)$ or practical $(7.48,1.70)$ means and standard deviation $(\mathrm{F}=2.224, p=$ .018 ) indicating significantly higher affective transcultural self-efficacy.

Using a Pearson product moment correlation, core selfevaluations were significantly related to all three subscales on the transcultural self-efficacy scale, specifically: cognitive ( $r$ $=.431, p=.000)$; affective $(r=.469, p=.000)$ and practical $(r$ $=.532, p=.000)$. Partial correlation was used to explore the relationship between core self-evaluations and transcultural self-efficacy while controlling for age, pre-licensure nursing education program, race, and satisfaction with current nursing position. An inspection of the zero order correlation $(r=$ $.417, p=.001$ ) for cognitive transcultural self-efficacy; .479, $p=.000$ for affective transcultural self-efficacy; and $.521, p$ $=.000$ for practical transcultural self-efficacy suggested that controlling for age ( $r=-.072, p=.57)$, pre-nursing education program $(r=-.081, p=.53)$, race $(r=.03, p=.78)$, and satisfaction with present nursing position $(r=-.121, p=.34)$ had very little effect on the strength of the relationship between core self-evaluations and transcultural self-efficacy.

\section{Discussion}

The findings from this study have implications for research and educational interventions focusing on nurses' abilities to provide culturally competent care. Using self-reported data from a sample of 71 registered nurses pursuing graduate education for the CNL role, we show strong positive correlations among respondents' self-perceptions and their confidence with providing nursing care to clients from culturally diverse backgrounds. Compared to other nursing samples reported in the literature ${ }^{[16-18,25]}$, the transcultural self-efficacy skills in this sample of racially diverse graduate nursing students were higher than pre-licensure nursing students but lower than nursing faculty (see Table 3 ). This result is anticipated because practicing nurses are more likely to have daily interaction with clients from racial and ethnic groups that may differ from their own, particularly in urban settings with a heterogeneous population. 
Table 3. Transcultural self-efficacy skills in different nursing samples

\begin{tabular}{|c|c|c|c|c|}
\hline Author & Sample & Cognitive & Practical & Affective \\
\hline Amerson (2010) & $\begin{array}{l}\text { BSN nursing students }(\mathrm{N}=60) \\
\text { Pre-intervention }\end{array}$ & $6.60(1.29)$ & $6.70(1.27)$ & $8.46(.94)$ \\
\hline Andrews et al. (2011) & $\begin{array}{l}\text { BSN nursing students }(\mathrm{n}=226) \text { combined } \\
\text { with graduate nursing students }(\mathrm{n}=29) \\
\text { Pre-intervention } \\
702 \text { RNs, } 91 \text { NPs }\end{array}$ & $5.35(\mathrm{SD}=$ not reported $)$ & 5.60 & 8.30 \\
\hline Jeffreys \& Dogan (2012) & $\begin{array}{l}\text { Associate Degree nursing students }(\mathrm{n}=147) \\
\text { Pre-intervention }\end{array}$ & $6.92(1.70)$ & $7.29(1.61)$ & $8.42(1.00)$ \\
\hline Kontzamanis (2013) & Associate Degree Nursing faculty $(\mathrm{N}=65)$ & $7.81(1.69)$ & $7.70(1.78)$ & $9.02(0.87)$ \\
\hline $\begin{array}{l}\text { Nokes \& Gilmartin } \\
\text { (current study) }\end{array}$ & New CNL graduate nursing students $(\mathrm{N}=71)$ & $7.42(1.64)$ & $7.48(1.70)$ & $8.68(1.13)$ \\
\hline
\end{tabular}

Core self-evaluations in this sample of CNL graduate students were lower than in other samples reported in the nursing-specific leadership research (see Table 1). This result may be due, in part, to the demographic characteristics of the participants. Judge and Hurst ${ }^{[34]}$ found that members of traditionally disadvantaged groups tended to have lower core selfevaluations than members of racial majority groups. CSE are significantly correlated with childhood indicators such as socioeconomic level and parents' educational attainment and occupational status. That is, experiences from childhood shape perceptions about one's worthiness, effectiveness and capabilities as a person. Our sample is comprised of approximately 54\% racial minorities. Although our respondents reflect the racial, ethnic and socioeconomic diversity of nurse graduates from a large, public higher education system located in an urban setting with a heterogeneous population, the nurses in our study are more racially and ethnically diverse than the nurses participating in prior studies examining core self-evaluations in work settings. ${ }^{[23,24]}$

The relatively low core self-evaluations for this group of nurses in the early phases of graduate education for the CNL role, is less than desirable for persons who are embracing a new nursing role that requires leadership skills to inspire followers. Although core self-evaluations are a relatively stable personality trait, evidence suggests that carefully formulated interventions can positively change the way a person appraises their capabilities in the work environment. ${ }^{[35]}$ For example, employees with high core self-evaluations may have the confidence to rely on their own merit in securing important organizational outcomes such as ensuring quality patient care. In comparison, employees with low core selfevaluations may have stronger tendencies to engage in social undermining. Social undermining involves negative evaluations of a particular person in a way that undermines that person's abilities to achieve his or her goals. Individuals with low self-evaluations are more likely to criticize others at work so to discredit the accomplishments of others, with the goal of making himself or herself look better in terms of his or her abilities to achieve success. ${ }^{[36]}$ For example, a CNL who has low core self-evaluations may discredit the contributions of the senior nursing staff in identifying and implementing improvement projects in the clinical microsystem.

Although core self-evaluations are a relatively stable personality characteristic, educational programs that consider strategies to impact on core self-evaluations in order to assist professionals to appraise their workplace challenges in a more positive framework may be one approach to addressing this conflict. The detrimental effects of low core selfevaluations may be due to individuals' inability to respond to positive stimuli in their environments. Strong situational reinforcements leading the person to focus on the positive aspects of their situation could help circumvent the negative effects of core self-evaluations on individuals' perceptions of their world. ${ }^{[35]}$

\subsection{Implications for research}

The results of this study point to new avenues for research. First, additional studies should examine the direction of the relationship between transcultural self-efficacy and core selfevaluations. New studies testing causal pathways among variables focused on nurses' knowledge, skills, attitudes and self-confidence in delivering culturally-appropriate care will be useful to determine the most effective training and organizational development approaches. Second, because we rely on self-report data, future research could incorporate observations and consumer feedback about providers' skills in delivering culturally appropriate care. Finally, longitudinal studies following nurses throughout the CNL graduate program, clinical immersion and role transition experiences would provide valuable information about the process of developing confidence in delivering culturally-appropriate, high quality nursing care. 


\subsection{Implications for practice}

Transcultural self-efficacy among this group of CNL graduate students in the early phase of the master's program was acceptable. Current evidence suggests that training programs focused on improving provider's cultural competence have a positive effect on patient outcomes, although the evidence is mixed in terms of identifying clear guidelines for training initiatives. ${ }^{[18,37,38]}$ Despite the limitations of the current research on the development of transcultural self-efficacy skills, provider training is an important component for practice change to reduce disparities in care for racial and ethnic minorities. ${ }^{[2]}$ Because CNLs are tasked with quality improvement and outcomes management in the clinical microsystem, cultural competence is an important skill for these nurse leaders.

An important component of leadership development focuses on cultivating self-awareness and insight skills into one's strengths and weakness to lead others in organizational settings. ${ }^{[39]}$ In turn, self-assessment data is used to create targeted development activities to address individuals' shortcoming that may hinder their effectiveness as leaders and change agents. Incorporating personality assessments such as the core-self evaluations as part of the leadership development activities for nurses pursuing the CNL role is an important activity. More positive core self-evaluations are associated with career success and success in implementing the new CNL role is essential for its adoption within diverse healthcare settings. If core self-evaluations are lower than desirable, then focused interventions taking place during the CNL education and socialization process, can target increasing this relatively stable personality trait. ${ }^{[40]}$ For example, the CNL student who is anxious and quick tempered (i.e., demonstrates high neuroticism/emotionally labial) could receive coaching to identify situational triggers and develop strategies to reduce their anxiety at work.

\section{Limitations}

The limitations of our study should be considered when interpreting the findings. First, our respondents reflect the racial and ethnic diversity of an urban setting and are not representative of the larger nursing population in either the geographic region, or the US, thus limiting the generalizability of our findings. Second, because our data come from a larger program evaluation study we only focus on nurses pursuing the CNL master's degree. New studies comparing nurses pursuing other graduate-prepared nursing roles

\section{REFERENCES}

[1] National Research Council. How Far Have We Come in Reducing Health Disparities? Progress Since 2000: Workshop Summary. Washington, DC: The National Academies Press: 2012. would be useful to generate new knowledge on the effect of personality on transcultural self-efficacy. We rely on selfreported data using a convenience sample which increases the threat of single source bias, particularly social desirability bias, because respondents are asked to rate their confidence with carrying out key activities of professional nursing practice. ${ }^{[41,42]}$ Social desirability bias occurs when individuals tend to present themselves in a favorable light, regardless of their true feelings about an issue or topic. ${ }^{[41]}$ Following recommendations by Podsakoff and colleagues ${ }^{[41]}$ and Conway $\&$ Lance, ${ }^{[42]}$ we used two procedural remedies to reduce the threat of common source bias in surveys examining individuals' behavior and perceptions related to work. These include: the use of valid and reliable indices and guaranteeing that participant's responses were strictly anonymous to the program faculty since data were collected by external evaluators and data analysis only commenced once data collection was completed.

Perhaps there are differences in core self-evaluations that motivate choosing different roles in nursing requiring advanced nursing education. This article presents baseline data for the graduate nursing students beginning their educational journey to prepare for the CNL role. It would be interesting to see if there were changes over time as students' progress through the program.

\section{Conclusions}

This descriptive study applies the model of core selfevaluations-career success relationship ${ }^{[28]}$ to a graduate nursing student sample and studies the relationship between an interpersonal construct, cultural competency, and a personality disposition, core self-evaluations. Although core selfevaluations are a relatively stable personality characteristic, educational programs that consider strategies to impact on core self-evaluations in order to assist professionals to appraise their workplace challenges in a more positive framework may be one approach for workforce development.

\section{ACKNOWLEDGEMENTS}

The research is Funded, in part, by a grant from the Health Services Resource Administration: Clinical Nurse Leader in Safety Net Settings (DO9HP14819) (2009 to 2012).

\section{CONFLicts OF INTEREST Disclosure}

The authors declare that there is no conflict of interest statement.

[2] Clarke AR, Goddu AP, Nocon RS, et al. Thirty years of disparities intervention research: What are we doing to close racial and ethnic gaps in health care? Medical Care. 2013; 51(11): 1020-1026. PMid:24128746 
[3] The Patient Protection and Affordable Care Act. 2010. Available from: http://www.gpo.gov/fdsys/pkg/BILLS-111hr3590en r/pdf/BILLS-111hr3590enr.pdf

[4] American Nurses Association (nd). Code for Ethics for Nurses. 2015 Available from: http://nursingworld.org/MainMenuCateg ories/ThePracticeofProfessionalNursing/EthicsStand ards/CodeofEthics.aspx

[5] Office of Minority Health. What is Cultural Competency? 2013 Available from: http://minorityhealth.hhs.gov/omh/brows e. $\operatorname{aspx} ? \operatorname{lvl}=1 \& l v l i d=6$

[6] Weech-Maldonado R, Elliott M, Pradham R, et al. Can hospital cultural competence reduce disparities in patent experiences with care? Medical Care. 2002; 50: S48-S55. PMid:23064277 http://dx.doi.org/10.1097/MLR. Ob013e3182610ad1

[7] Institute for Healthcare Improvement (nd). The IHI Triple Aim. Available from: http://www.ihi.org/Engage/Initiatives/T ripleAim/Pages/default.aspx

[8] Jeffers B, Astroth K. The Clinical Nurse Leader: Prepared for an era of healthcare reform. Nursing Forum. 2013; 48(3): 223-229. PMid:23889201 http://dx.doi.org/10.1111/nuf.12032

[9] American Association of Colleges of Nursing. Implementing a new nursing role-the Clinical Nurse Leader-for improved patient care outcomes. Final Report of the Implementation Task Force, American Association of Colleges of Nursing, Washington: D.C. 2007.

[10] American Association of Colleges of Nursing. Competencies and Curricular Expectations for Clinical Nurse Leader Education and Practice. American Association of Colleges of Nursing, Washington: D.C. 2013

[11] Reid K, Dennison P. The Clinical Nurse Leader (CNL)®: Point-ofCare safety clinician OJIN: The Online Journal of Issues in Nursing. 2012; 16(3).

[12] Bender M, Connelly C, Glaser D, et al. Clinical Nurse Leader impact on microsystem care quality. Nursing Research. 2012; 61(5): 326-332. PMid:22935769 http://dx.doi.org/10.1097/NNR . 0 b013e318265a5b6

[13] Hix C, McKeon K, Walters S. Clinical Nurse Leader impact on clinical microsystem outcomes. Journal of Nursing Administration. 2009; 39(2): 71-76. PMid:19190423 http://dx.doi.org/10.1097/N NA. Ob013e318195a612

[14] Bender M. The current evidence base for the Clinical Nurse Leader: A narrative review of the literature. Journal of Professional Nursing. 2014; 30(2): 110-123. PMid:24720939 http://dx.doi.org/10. $1016 / j$. profnurs . 2013.08.006

[15] Ong-Flaherty C. Clinical nurse leaders in the community: Building an academic faculty practice partnership. Journal of Nursing Education and Practice. 2015; 5(3): 44-49.

[16] Amerson R. The impact of service-learning on cultural competence. Nursing Education Perspectives. 2010; 31(1): 18-22. PMid:20397475

[17] Andrews M, Thompson T, Wehbe-Alamah H, et al. Developing a culturally competent workforce through collaborative partnerships. Journal of Transcultural Nursing. 2011; 22(3): 300-306. PMid:21666146 http://dx.doi.org/10.1177/1043659611404214

[18] Kontzamanis E. An Investigation of the relationship between nursing faculty attitudes toward culturally diverse patients and Transcultural Self-Efficacy. Doctoral dissertation. New York: City University of New York; 2013; 98p.

[19] Kim SH. Transcultural Self-efficacy and Educational Needs for Cultural Competence in Nursing of Korean Nurses. Journal of Korean Academic Nursing. 2013; 43(1): 102-113. PMid:23563073 http://dx.doi.org/10.4040/jkan.2013.43.1.102
[20] Gilmartin MJ. Variations in Clinical Nurse Leaders' confidence with performing the core role functions. Journal of Professional Nursing. Advanced on-line release. 2013 November 18.

[21] Dzurec LC, Allchin L, Engler AJ, et al. Toward a qualified yes: personal characteristics of post baccalaureate nursing students and implementation of the Clinical Nurse Leader role. Journal of Professional Nursing. 2006; 22(1); 15-22. PMid:16459285 http://dx.d oi.org/10.1016/j.profnurs.2005.12.001

[22] Judge T. Core self-evaluations and work success. Current Directions in Psychological Science. 2009; 18(1): 58-62. http://dx.doi.o $\mathrm{rg} / 10.1111 / \mathrm{j} .1467-8721.2009 .01606 . \mathrm{x}$

[23] Laschinger H, Finegan J, Wilk P. Situational and dispositional influences on nurses' workplace well-being. Nursing Research. 2011; 60(2): 124-131. PMid:21317827 http://dx.doi.org/10.1097 /NNR.0b013e318209782e

[24] Laschinger H, Finegan J. Situational and dispositional predictors of nurse manager burnout: A time-lagged analysis. Journal of Nursing Management. 2008; 16: 601-607. PMid:18558930 http: //dx.doi.org/10.1111/j.1365-2834.2008.00904.x

[25] Jeffreys MR, Dogan E. Evaluating the influence of cultural competence education on students' Transcultural Self-Efficacy perceptions. Journal of Transcultural Nursing. 2012; 23(2): 188 197. PMid:22052092 http://dx.doi.org/10.1177/104365961 1423836

[26] Jeffreys MR. Teaching cultural competence in nursing and health care: Inquiry, action, and innovation (2nd ed.). New York, NY: Springer.

[27] Judge T, Bono J, Erez A, et al. Core Self-Evaluations and job and life satisfaction: The role of Self-Concordance and Goal Attainment. Journal of Applied Psychology. 2005; 90(2); 257-268. PMid:15769236 http://dx.doi.org/10.1037/0021-9010.90 .2 .257

[28] Judge T, Kammeyer-Mueller J. Implications of core self-evaluations for a changing organizational context. Human Resources Review. 2011; 21: 331-341. http://dx.doi.org/10.1016/j.hrmr.20 10.10 .003

[29] Judge T, Erez A, Bono J, et al. The Core Self-Evaluations Scale (CSES): Development of a measure. Personnel Psychology. 2003; 56 : 303-331. http://dx.doi.org/10.1111/j.1744-6570.2003.tb00152.x

[30] Chang Y, Li H, Wu C, et al. The influence of personality traits on nurses' job satisfaction in Taiwan. International Nursing Review. 2010; 57: 478-484. PMid:21050200 http://dx.doi.org/10.11 $11 / j \cdot 1466-7657.2010 .00825 \cdot x$

[31] Almost J, Doran D, Hall L, et al. Antecedents and consequences of intra-group conflict among nurses. Journal of Nursing Management. 2010; 18: 981-992. PMid:21073570 http://dx.doi .org/10.11 $11 / j .1365-2834.2010 .01154 . x$

[32] Jeffreys MR, Dogan E. Factor analysis of the Transcultural Selfefficacy Tool (TSET). Journal of Nursing Measurement. 2010; 18(2): 120-139. http://dx.doi.org/10.1891/1061-3749.18.2.120

[33] Health Resources and Services Administration, U.S. Department of Health and Human Services. The Registered Nurse Population: Initial Findings from the 2008 National Sample Survey of Registered Nurses. 2010; Available from: http://bhpr.hrsa.gov/health workforce/rnsurveys/rnsurveyinitial2008.pdf

[34] Judge T, Hurst C. Capitalizing on one's advantages: Role of Core Self-Evaluations. Journal of Applied Psychology. 2007; 92(5): 1212 1227. PMid:17845081 http://dx.doi.org/10.1037/0021-901 0.92 .5 .1212

[35] Chu-Hsiang CD, Ferris D, Johnson R. Core self-evaluations: A review and evaluation of the literature. Journal of management. 2012; 38(1): 81-128. http://dx.doi.org/10.1177/0149206311419 661 
[36] Greenbaum R, Mawritz M, Eissa G. Bottom-Line mentality as an antecedent of social undermining and the moderating roles of Core Self-Evaluations and conscientiousness. Journal of Applied Psychology. 2012; 97(2): 343-359. PMid:22268488 http://dx.doi.org $/ 10.1037 / \mathrm{a} 0025217$

[37] Lie D, Lee-Rey E, Gomez A, et al. Does cultural competency training of health professionals improve patient outcomes? A systematic review and proposed algorithm for future research. Journal of General Internal Medicine. 2010; 26(3): 317-25. PMid:20953728 http://dx.doi.org/10.1007/s11606-010-1529-0

[38] Larsen R, Reif L. Effectiveness of cultural immersion and culture classes for enhancing nursing students' Transcultural Self-Efficacy. Journal of Nursing Education. 2011; 50(6): 350-354. PMid:21323246 http://dx.doi.org/10.3928/01484834-20110214-04

[39] Anderson J, Kole SR. Leadership effectiveness and development: Building self-awareness and insight skills. In The Handbook for teaching leadership: Knowing, doing and being. S. Snook, N. Nohria \& R. Khurana (eds). Sage: Thousand Oaks, CA. 2012.

[40] Stanhope DS, Pond III SB, Surface EA. Core Self-Evaluations and training effectiveness: Prediction through motivational intervening mechanisms. Journal of Applied Psychology. 2013; 98(5): 820-831. PMid:23565894 http://dx.doi.org/10.1037/a0032599

[41] Pondsakoff PM, MacKenzie SB, Lee JY, et al. Common methods bias in behavioral research: A critical review of the literature and recommended remedies. Journal of Applied Psychology. 2003; 88(5): 879903. PMid:14516251 http://dx.doi.org/10.1037/0021-901 0.88 .5 .879

[42] Conway JM, Lance CE. What reviewers should expect from authors regarding common methods bias in organizational research. Journal of Business Psychology. 2010; 25: 325-334. http://dx.doi.org /10.1007/s10869-010-9181-6 